\title{
Compound flood potential from storm surge and heavy precipitation in coastal China: dependence, drivers, and impacts
}

\author{
Jiayi Fang ${ }^{1}$, Thomas Wahl ${ }^{2}$, Jian Fang ${ }^{3}$, Xun Sun ${ }^{1}$, Feng Kong ${ }^{4}$, and Min Liu ${ }^{1}$ \\ ${ }^{1}$ Key Laboratory of Geographic Information Science (Ministry of Education), School of Geographic Sciences, \\ East China Normal University, Shanghai, 200241, China \\ ${ }^{2}$ Department of Civil, Environmental, and Construction Engineering and National Center for Integrated Coastal Research, \\ University of Central Florida, 12800 Pegasus Drive, Orlando, FL 32816, USA \\ ${ }^{3}$ College of Urban and Environmental Science, Central China Normal University, Wuhan, 430079, China \\ ${ }^{4}$ College of Humanities and Development Studies, China Agriculture University, Beijing, 100083, China
}

Correspondence: Jiayi Fang (jyfang822@foxmail.com,jyfang@geo.ecnu.edu.cn)

Received: 20 July 2020 - Discussion started: 30 July 2020

Revised: 8 July 2021 - Accepted: 12 July 2021 - Published: 12 August 2021

\begin{abstract}
The interaction between storm surge and concurrent precipitation is poorly understood in many coastal regions. This paper investigates the potential compound effects from these two flooding drivers along the coast of China for the first time by using the most comprehensive records of storm surge and precipitation. Statistically significant dependence between flooding drivers exists at the majority of locations that are analysed, but the strength of the correlation varies spatially and temporally and depending on how extreme events are defined. In general, we find higher dependence at the south-eastern tide gauges (TGs) (latitude $<30^{\circ} \mathrm{N}$ ) compared to the northern TGs. Seasonal variations in the dependence are also evident. Overall there are more sites with significant dependence in the tropical cyclone (TC) season, especially in the summer. Accounting for past sea level rise further increases the dependence between flooding drivers, and future sea level rise will hence likely lead to an increase in the frequency of compound events. We also find notable differences in the meteorological patterns associated with events where both drivers are extreme versus events where only one driver is extreme. Events with both extreme drivers at south-eastern TG sites are caused by low-pressure systems with similar characteristics across locations, including high precipitable water content (PWC) and strong winds that generate high storm surge. Based on historical disaster damages records of Hong Kong, events with both extreme drivers account for the vast majority of damages and casualties, compared to univariate flooding events,
\end{abstract}

where only one flooding driver occurred. Given the large coastal population and low capacity of drainage systems in many Chinese urban coastal areas, these findings highlight the necessity to incorporate compound flooding and its potential changes in a warming climate into risk assessments, urban planning, and the design of coastal infrastructure and flood defences.

\section{Introduction}

Floods are among the costliest and deadliest disasters globally (Hu et al., 2018). In recent years, a series of devastating compound flooding events occurred, such as Hurricane Isaac in 2012, Typhoon Haiyan in 2013, Hurricane Irma and Hurricane Florence in 2018, and Typhoon Lekima in 2019. Despite improvements in flood defences, flood forecasting, and warnings, these flood events caused devastating impacts, in part due to the limited understanding of compound floods in coastal regions. Flooding along the coast can arise from three main sources: (1) extreme sea levels (comprised of storm surge, high astronomical tides, and/or waves (coastal flood)); (2) river discharge (fluvial flood); and (3) direct surface runoff from rainfall (pluvial flood) (Hendry et al., 2019). Floods in coastal areas are frequently caused by more than one driver and the impacts when they coincide are often much greater than from either flood driver occurring in isolation (Leonard et al., 2014; Zscheischler et al., 2018; Hao et al., 2018). Ex- 
ploring the probabilities of compound flood events and understanding their driving processes is important for flood mitigation and risk reduction in a warming climate (Wahl et al., 2015).

A growing number of studies investigated compound flooding in recent years. At the global scale, dependence between storm surge and river discharge has been investigated based on observational data (Ward et al., 2018) and model hindcasts (Bevacqua et al., 2020; Couasnon et al., 2020). The relationship between storm surge and wind waves was assessed by Marcos et al. (2019). At the regional scale, compound flood assessments have been undertaken for Australia (Zheng et al., 2013, 2014; Wu et al., 2018), the USA (Wahl et al., 2015), the UK (Svensson and Jones, 2002, 2004; Hendry et al., 2019), and Europe (Petroliagkis et al., 2016; Paprotny et al., 2018; Bevacqua et al., 2019; Ganguli and Merz, 2019). Other studies focused on specific locations, such as the Netherlands (van den Hurk et al., 2015); Fuzhou, China (Lian et al., 2013); Taiwan, China (Chen and Liu, 2014), or the North Sea (Khanal et al., 2019). Most of these studies investigated the dependence between two hazards, such as storm surge and river discharge, storm surge and waves, or storm surge and rainfall, thus assessing compound flood potential as opposed to actual compound flood risk.

For China, a comprehensive regional assessment of the compound flooding potential is currently missing. Low-lying coastal areas (elevation less than $10 \mathrm{~m}$ ) in China only account for $2 \%$ of the national land but account for more than $12 \%$ of the national population (Liu et al., 2015; Fang et al., 2020). At the same time, these areas are experiencing frequent coastal disasters from tropical cyclones (TCs) and storm surges, among others. Coastal flooding has caused more than USD 71 billion direct economic losses and 4376 fatalities in China from 1989 to 2014 (Fang et al., 2017). Flood risk is likely increasing in China due to climate change (most notably sea level rise), as well as human factors (e.g. humaninduced subsidence) (Fang et al., 2020, 2021; Jiang et al., 2020; Wu et al., 2005, 2017). Meanwhile, fast urbanization in China has led to more people and economic assets exposed to hazards (Fang et al., 2018; Du et al., 2018) and has also prompted irrational urban planning, increased areas of urban impervious surface, and low-capacity drainage systems (Cheng, 2020). For example, the capacity of the local drainage system of Shenzhen City is designed to drain the surface runoff associated with a 2-year return period (or 50\% annual exceedance probability) (Urban Planning \& Design Institute of Shenzhen, 2008). As drainage facilities are often under-designed and/or have not been upgraded, surface runoff during storms frequently exceeds the drainage capacity resulting in flooding damages in low-lying areas (Qin et al., 2013). Despite the relevance of compound flooding for coastal China, the associated probabilities and driving mechanisms have not been explored at broad spatial scales at the national level.
A limited number of studies have assessed different aspects of compound flooding for China. Lian et al. (2013) and $\mathrm{Xu}$ et al. (2014) investigated the joint probability, using copulas, of extreme precipitation and storm tide and associated changes for Fuzhou city. Both studies showed that the joint impacts from surge and precipitation were much higher than from each individually; this is currently ignored in the design of flood defences. Xing et al. (2015) analysed joint return periods of precipitation and runoff in the upper Huai River basin in China. Ye and Fang (2018) estimated compound hazard severity of TCs considering extreme wind and precipitation. Xu et al. (2019) investigated compound effects of rainfall and storm tides of the city of Haikou, China. Changes in storm surges and precipitation in China have also been investigated separately, showing significant increases in extreme precipitation in parts of the south-western and southern China coastal areas (Zhai et al., 2005). Similarly, significant increases in sea level extremes have been reported (Feng et al., 2015, 2019), and attributed to both changes in mean sea level (MSL) and in the wind-driven storm surge component (Feng and Tsimplis, 2014). However, these previous studies were mostly local, they neglected seasonal characteristics, and weather circulation patterns driving compound events were not assessed. In this study, we use the most comprehensive records of storm surge and precipitation to investigate dependences between the two flooding drivers and incidences of joint occurrences along with the synoptic weather patterns causing events where compound flood potential is high versus events where it is low. We also conduct a preliminary analysis of the potential impacts in terms of recorded losses and fatalities of past compound events caused by TCs.

In this context our four main objectives are the following: (1) assess the dependence between storm surge and precipitation for different thresholds for the full year and the summer and TC seasons; (2) examine the role of sea level rise in escalating compound flood potential; (3) identify large-scale weather systems leading to events with high versus low compound flood potential; and (4) explore possible contribution of compound flooding during past TC events.

\section{Data}

Most tide gauge (TG) data are kept confidential in China; thus, we obtained hourly sea level data of 11 TGs with at least 20-year lengths along the Chinese coast from the University of Hawaii Sea Level Center (Caldwell et al., 2015). Locations of TGs and the time series' lengths are shown in Fig. 1. The stations are located south of the Shandong Peninsula in China, where TC impacts are most severe (He et al., 2015). Nine of the 11 TG stations have about 20 years of data (19751997). Xiamen and Hong Kong have 46 years (1954-1997) and 52 years (1962-2014), respectively. 

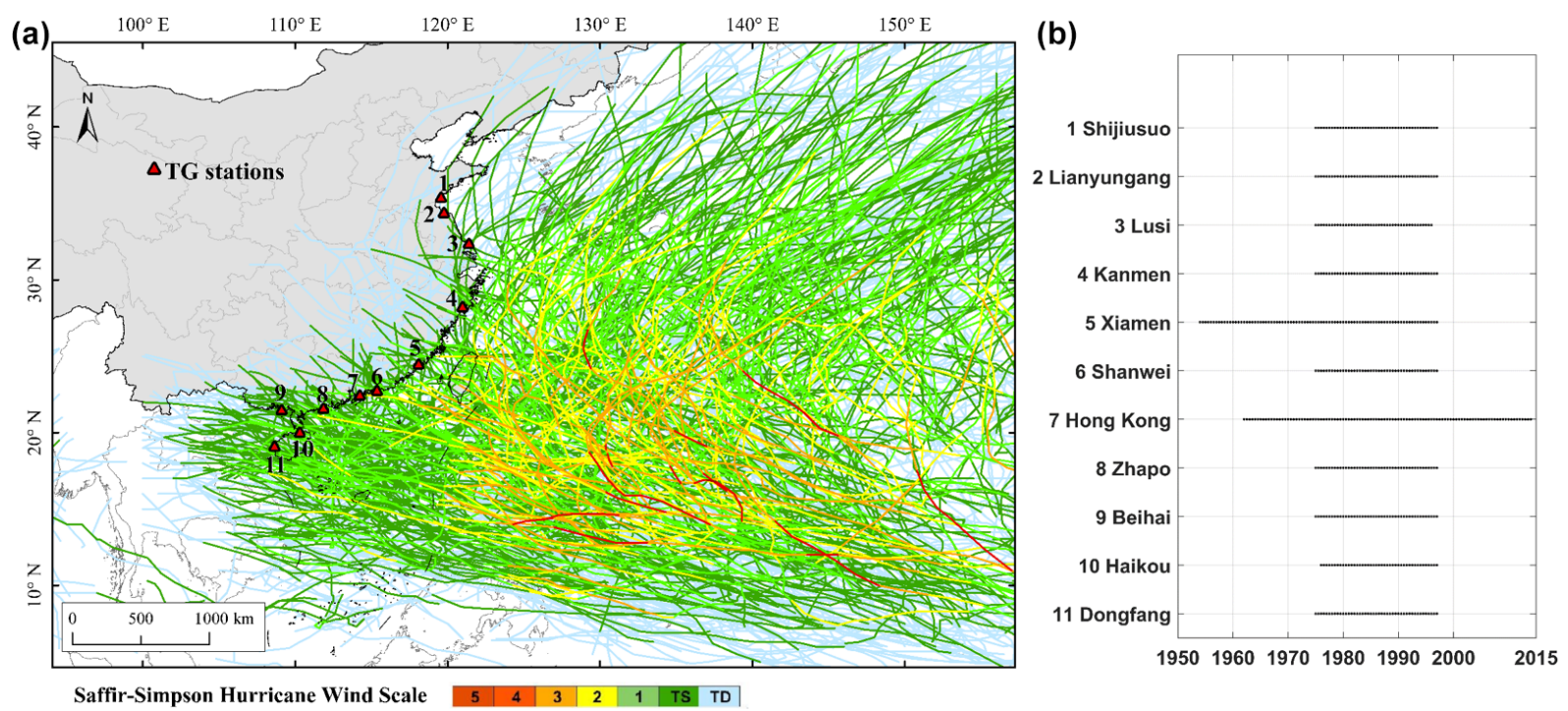

Figure 1. (a) Locations of 11 tide gauges and historical TC tracks for different intensities (only 1975-1997 shown here); (b) time periods covered by hourly sea level data at the 11 tide gauges.

Storm surge is extracted using the MATLAB t_tide package (Pawlowicz et al., 2002) by applying a year-by-year harmonic tidal analysis with 67 constituents. This also effectively removes the MSL influence including the long-term trend in MSL as well as the year-to-year and decadal variability (Wahl et al., 2015). The data have been checked for common errors, and $75 \%$ completeness of each year is required. An offset of $1.02 \mathrm{~cm}$ in the Hong Kong data in 1986/87 (due to changes in the TG location) is adjusted following Ding et al. (2002).

Daily cumulative precipitation records from 1951-2015 are collected from China Meteorological Administration. The closest meteorological station is chosen to match each TG station, and the distance between them is less than $25 \mathrm{~km}$ for 9 out of 11 TGs (TG2 with $29 \mathrm{~km}$ and TG8 with $34 \mathrm{~km}$ ). The time series of precipitation observations are usually longer and more complete than TG observations; thus TG data availability determines the lengths of overlapping periods available for the dependence analysis presented here.

To identify weather patterns typically associated with events that have high compound flood potential versus those that have low potential, sea level pressure (SLP), precipitable water content (PWC), and wind fields are used from the Twentieth Century Reanalysis Project Version 2c (Compo et al., 2011).

To assess the impacts of past TC events where both flooding drivers were extreme versus events where only one was extreme, we employ a damage database developed by Yap et al. (2015). It includes historical TC records from 1951 to 2012. The database contains information of 853 TCs with direct normalized economic loss (in USD), death toll, and number of people affected.

\section{Methodology}

\subsection{Defining compound events and dependence analysis}

Compound events have been defined in different ways in the past, either based on impact information (which we do not have) or based on the severity of the flooding drivers involved, assuming that at least one is extreme. In our study, we adopt the latter approach to account for the fact that the combination of storm surge and precipitation can exacerbate flood impacts in different ways (Wahl et al., 2015). First, both heavy precipitation and extreme sea levels (storm surge with high tides) can coincide, leading to more severe floods. This often happens during TC events. Second, impacts of a storm surge already causing flooding will increase when significant precipitation occurs at the same time, although the precipitation itself may not be considered extreme. Third, a moderate storm surge can block freshwater water drainage and high precipitation occurring at the same time can lead to more severe flooding (as compared to the same rain event coinciding with low sea level). To illustrate the definition, time series of daily maximum storm surge are plotted against records of daily cumulative precipitation for Kanmen (TG4) in Fig. 2. In the following analysis, three distinct cases are considered. First, Zone 1 shows the events with joint occurrence of high storm surge and heavy precipitation. Second, "Zone $1+$ Zone 3" refers to high storm surge with or without heavy precipitation. Third, "Zone 1+Zone 2" refers to heavy precipitation with or without high storm surge. These three combinations capture all of the above-mentioned mechanisms. We select extreme storm surge and the corresponding precipitation within $\pm 1 \mathrm{~d}$ of the surge or select extreme pre- 


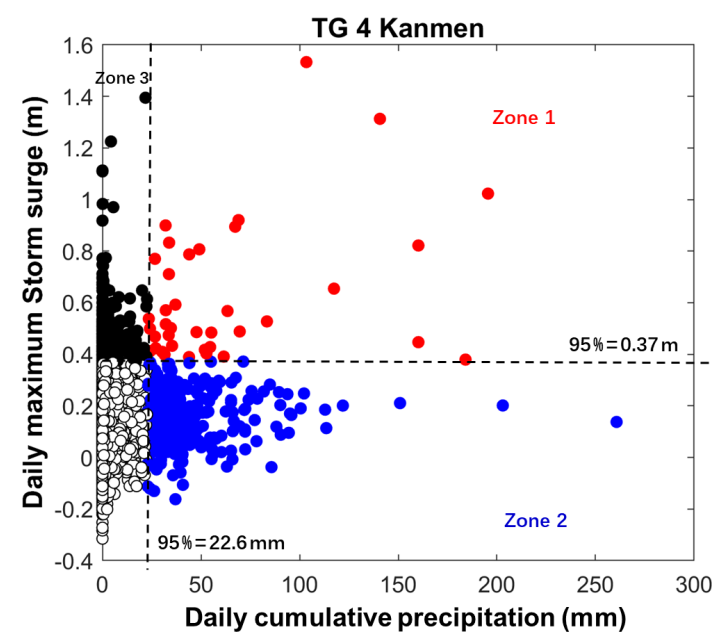

Figure 2. Daily maximum storm surge plotted against daily cumulative precipitation for threshold of $95 \%$. Red dots (plotted in Zone 1) show joint occurrence of high storm surge and heavy precipitation, whereas blue (Zone 2) and black (Zone 3) dots define events where only one flooding driver is extreme.

cipitation and the corresponding storm surges within $\pm 1 \mathrm{~d}$ of the precipitation.

We use the peaks-over-threshold (POT) method to select extreme events. The POT method refers to selecting events over a high threshold within a certain time span. The annual maximum approach is widely used for sampling extreme events. However, it would lead to small sample sizes here as time series of 9 out of 11 TGs in China only have around 23 years of data. Furthermore, the second or third largest values in a given year may be larger than the annual maximum in another year (Coles et al., 2001; Arns et al., 2013). To test the sensitivity of the results to the threshold selection, we employ thresholds related to eight percentiles ranging from $95 \%$ to $99.5 \%$, i.e. $95 \%, 96 \%, 97 \%, 98 \%, 98.5 \%, 99 \%, 99.25 \%$, and $99.5 \%$. Independence of the threshold exceedances is achieved using a declustering time of $3 \mathrm{~d}$.

Kendall's rank correlation coefficient $\tau$ is employed to measure dependence between storm surge and precipitation. In Zone 1+Zone 3, storm surges sometimes could occur without any precipitation, and this leads to ties (i.e. several zero values) affecting the dependence analysis. We use the same method as suggested in Kojadinovic and Yan (2010) and Wahl et al. (2015) by assigning ranks randomly, repeating the procedure 100 times and calculating the average rank correlation. To better understand the influence of seasonality, dependence is assessed for the full year as well as for summer (June to August) and the TC season (July to October).

\subsection{Effects from sea level rise on compound flood potential}

To test how the inclusion of sea level rise affects joint occurrences of flooding drivers, we count the occurrences between storm surge and precipitation with or without MSL. The effects of MSL are initially removed during the harmonic tidal analysis. We repeat the same sampling approach as outlined above but keep the MSL influence and extract surge events by only removing the tidal influence, i.e. total water level minus tide. Because of the inclusion of MSL and the resulting nonstationarity in the data, we can not carry out the dependence analysis in the same way as before. Thus, we simply count the number of pairs in Zone 1, Zone 1+Zone 3 and Zone $1+$ Zone 2 with and without MSL and compare them.

\subsection{Weather patterns driving events with high and low compound flood potential}

To investigate the meteorological patterns that drive events with high and low compound flood potential, we select a threshold of $98 \%$. We consider events with high compound flood potential to fall into Zone 1 in Fig. 2. Events with low compound flood potential fall in Zone 2 or Zone 3 in Fig. 2. SLP, PWC, and wind fields from the days when the events occurred are selected and averaged into composites to represent reference synoptic-scale weather patterns favouring compound flooding.

\subsection{Losses of past TC events where compound flood potential was high or low}

To quantify the differences in impacts caused by past TCs when compound flood potential was high or low, we use a TC damage database developed by Yap et al. (2015) for Hong Kong as a case study. We identify events with high/low compound flood potential in the same way as we did for the synoptic weather type analysis, then match the days when the events occurred with records in the database; the latter includes information on death toll, people affected, and economic losses.

\section{Results}

\subsection{Dependence between storm surge and precipitation and seasonal variation}

Figure 3 shows the Kendall dependence between all pairs of daily maximum storm surge and daily cumulative precipitation (Fig. 3a), as well as pairs in Zone 1 (Fig. 3b), pairs in Zone 1+Zone 3 (Fig. 3c), and pairs in Zone $1+$ Zone 2 (Fig. 3d), respectively. Figure $3 \mathrm{~b}-\mathrm{d}$ show the maximum dependence for thresholds running from $95 \%$ to $99.5 \%$. As expected, the three cases where events above high thresholds are collated have relatively higher dependence compared to when all data are used. For Zone 1, most TGs show insignificant dependence indicating a limited number of joint occurrences. For Zone 1+Zone 3, south-east coastal China, which is more affected by TCs (Fig. 1), exhibits higher dependence than the northern part. Overall, Zone $1+$ Zone 3 
(a)

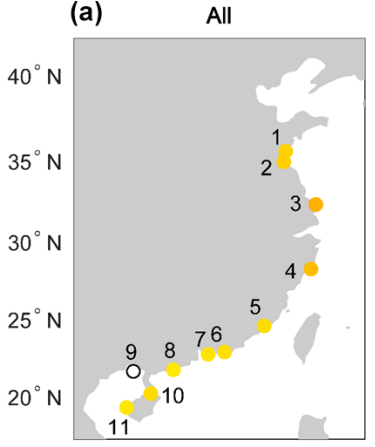

(c) Zone $1+$ Zone 3

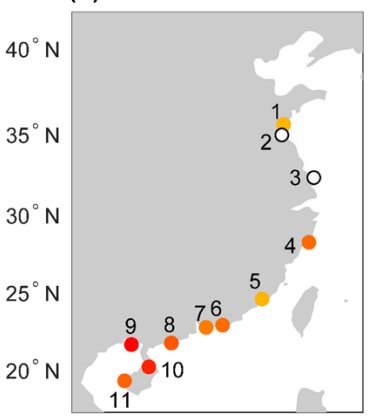

$105^{\circ} \mathrm{E} 110^{\circ} \mathrm{E} 115^{\circ} \mathrm{E} 120^{\circ} \mathrm{E}$

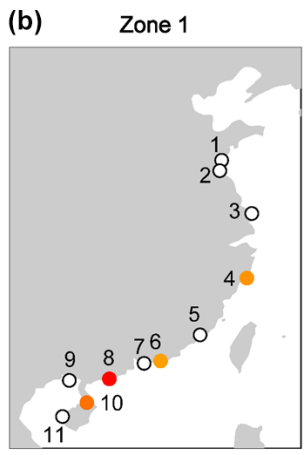

(d) Zone $1+$ Zone 2

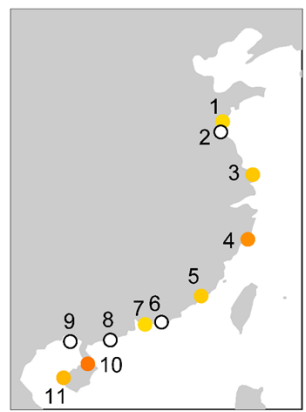

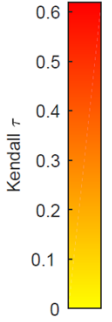

2.

Figure 3. Kendall dependence between storm surge and precipitation. (a) Daily maximum storm surge and daily cumulative precipitation; (b) pairs in Zone 1; (c) pairs in Zone 1+Zone 3; (d) pairs in Zone $1+$ Zone 2. (b-d) The maximum dependence for thresholds running from $95 \%$ to $99.5 \%$. White dots refer to insignificant dependence $(10 \%$ level).

dependence is also higher than Zone $1+$ Zone 2 dependence, and we identify more locations with significant dependence: nine TGs in Zone $1+$ Zone 3 and seven TGs in Zone $1+$ Zone 2, respectively.

Kanmen (TG4) and Haikou (TG10) show relatively high dependence for all cases. Shanwei (TG6) and Zhapo (TG8) show high positive dependence in Zone 1 and Zone $1+$ Zone 3 but insignificant dependence in Zone $1+$ Zone 2 , indicating that high storm surge is often accompanied by high rainfall but not the other way round. The opposite is true for Lusi (TG3), which has positive dependence in Zone $1+$ Zone 2 but insignificant dependence in Zone $1+$ Zone 3 .

We also test impact of the thresholds (95\% to $99.5 \%$ ) which can influence the correlation (Fig. S1 in the Supplement). At most locations the dependence increases when higher thresholds are used to sample extremes. There are exceptions however; for example, Haikou (TG10) in Zone $1+$ Zone 2 shows higher dependence with a threshold of $99 \%$ than $99.5 \%$. At some TGs dependence becomes insignificant due to small sample sizes when thresholds are very high, indicating the trade-off between bias and variance in the threshold selection. Thresholds for compound events

are very localized and highly dependent on the underlying data, and various methods exist to select bivariate extremes (Salvadori et al., 2016). We did not compare those methods here as it would go beyond the scope of our study.

To better understand the timing of events with relatively higher compound flood potential, the influence of seasons is investigated. TCs are active over the western North Pacific during July to October (He et al., 2015). Thus, three periods are considered: TC season (July-October), summer (June-August), and the whole year. The seasonal dependences are displayed in Fig. 4. It shows that dependences in Zone $1+$ Zone 3 and Zone $1+$ Zone 2 are stronger than Zone 1 dependence for all seasons. Zone $1+$ Zone 3 also shows stronger significant dependence than Zone $1+$ Zone 2 .

For Zone 1+Zone 3, multiple TGs show stronger dependence in summer and in the TC season compared to the whole year, such as Kanmen (TG4), Shanwei (TG6), and Hong Kong (TG7). Zhapo (TG8) shows insignificant dependence in Zone $1+$ Zone 2, while significant positive dependence is found in Zone $1+$ Zone 3. TGs from Kanmen (TG4) to Dongfang (TG11) with latitudes less than $30^{\circ} \mathrm{N}$ are most affected by TCs and show high dependence for Zone $1+$ Zone 3, especially in summer and in the TC season. Xiamen (TG5) is an exception, likely because the island of Taiwan weakens the intensity of TCs before reaching Xiamen.

Dependence also varies with the threshold selection when performing the seasonal analysis. To illustrate this, five TGs are selected as examples in Fig. 5. Dependence continuously increases with higher thresholds. Again, for some TGs, dependence becomes insignificant for high thresholds, especially when records are short. For some TGs, the dependences in TC season are similar with the whole year, like Shanwei (TG6) and Zhapo (TG8) in Zone 1+Zone 3, indicating that most events with compound flood potential occur in the TC season. For example, $62 \%$ compound events (Zone $1+$ Zone 3 in Fig. 2) for Shanwei (TG6) and $64 \%$ for Zhapo (TG8) occurred in the TC season.

South-east coastal China is affected not only by TCs but also by summer monsoon precipitation from the Northwest Pacific Subtropical High. The summer monsoon brings continuous precipitation from June to August in southern China. With the coincidence of frequent storm surge in July and August, it may explain the higher dependence in the summer compared to the TC season. It has been reported that an abrupt increase of intense TCs occurred in September after the mid-2000s for southern China (He et al., 2016), which could affect the seasonality of compound events. However, from the results shown in this study, this pattern is not captured due to limited observation (most observations end in 1997). 

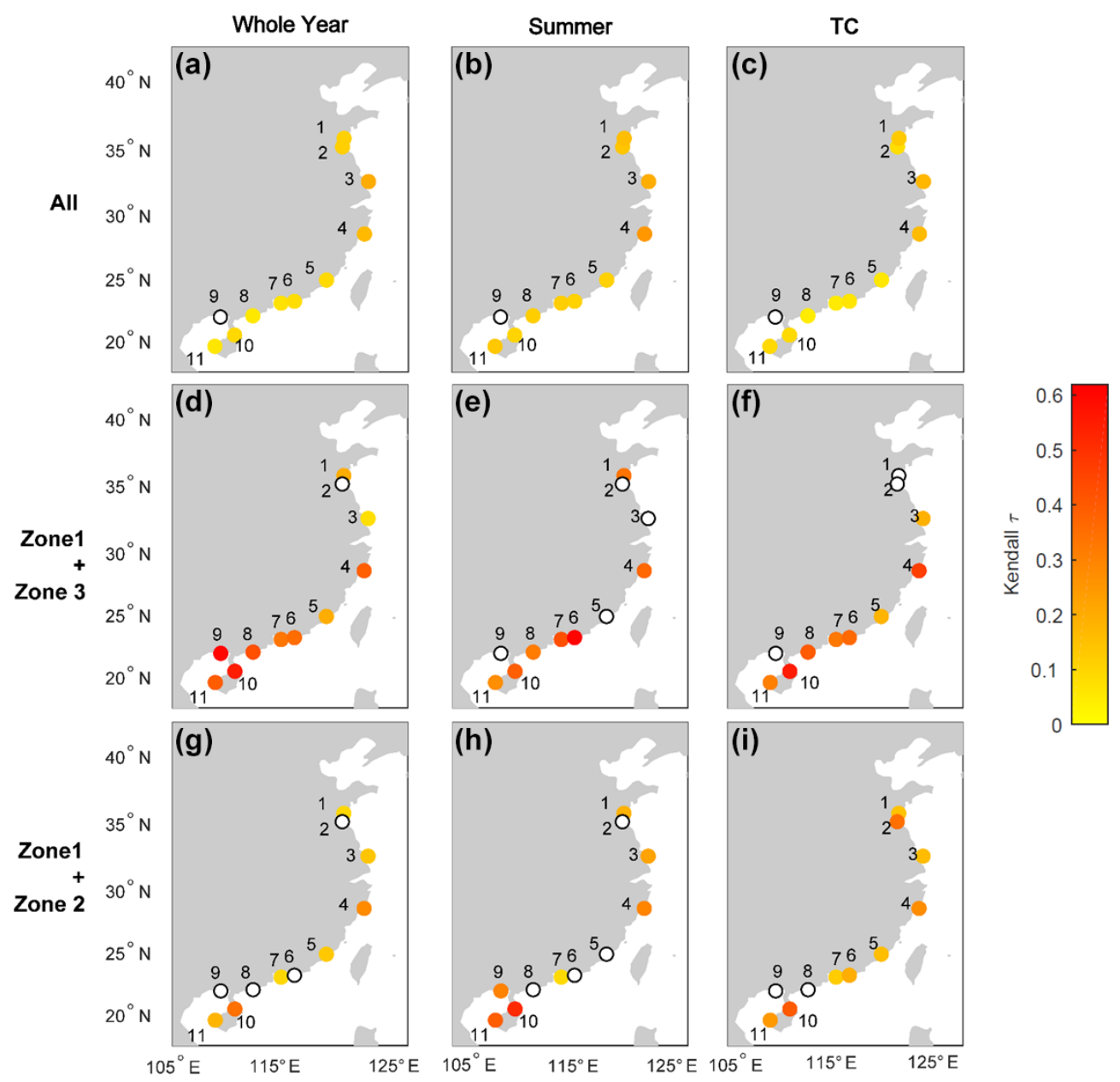

Figure 4. Kendall dependence between storm surge and precipitation in summer, the TC season, and the whole year. (a-c) Daily maximum storm surge and daily cumulative precipitation, (d-f) pairs in Zone 1+Zone 3, and (g-i) pairs in Zone 1+Zone 2; maximum dependence for thresholds running from $95 \%$ to $99.5 \%$ is shown. White dots refer to insignificant dependence (10\% level).

\subsection{Effects of sea level rise on compound flood potential}

To better understand the effect of sea level rise on compound flood potential, we count occurrences between storm surge and precipitation with or without MSL; the differences are displayed in Fig. 6 for three cases. For Zone 1, 8 out of 11 TGs show an increase of joint occurrences when MSL influence is included, whereas the number at Haikou (TG10) remains unchanged. At Lianyungang (TG2) and Beihai (TG9), only one joint occurrence event is identified when MSL is removed, while this number increases to 22 and 26, respectively, with MSL included. Similar patterns are observed for Zone $1+$ Zone 3 and Zone $1+$ Zone 2 with most TGs showing increases of joint occurrences. For Zone $1+$ Zone 3, 6 out of 11 TGs show a relatively strong increase and the remainder show a slight decrease. For Zone $1+$ Zone 2, more joint occurrences are observed at 10 out of 11 TGs. Lianyungang (TG2), Xiamen (TG5), Hong
Kong (TG7), and Beihai (TG9) show the largest increases when MSL is included.

The results indicate that coastal China will experience an increasing frequency of events with high compound flood potential under future MSL rise. This is in line with Moftakhari et al. (2017) and Bevacqua et al. (2019), who also report that MSL rise will lead to more compound events. Sea level rise not only increases the probability of coastal flooding from storm surges (Buchanan et al., 2017), but also poses an additional threat for coastal communities susceptible to compound flooding. Meanwhile, other flood drivers, such as precipitation, river discharge and waves, can also exhibit nonstationarity leading to increased (compound) flood risk (Kundzewicz et al., 2019). Observations from the last five decades and numerical model studies (Lai et al., 2020) indicate a slowdown of TCs, which would likely favour more extreme rainfall during the events as compared to fastmoving TCs. 
(a)

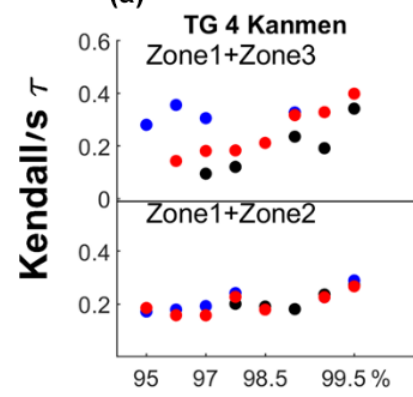

(d)

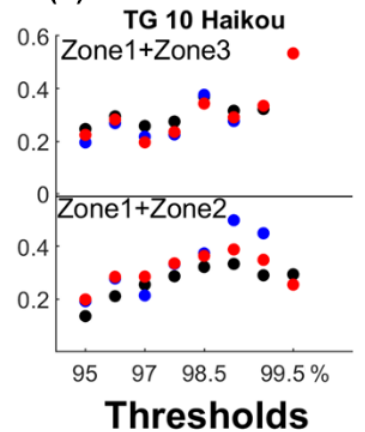

(b)

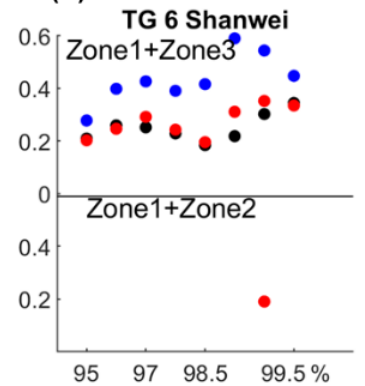

(e)

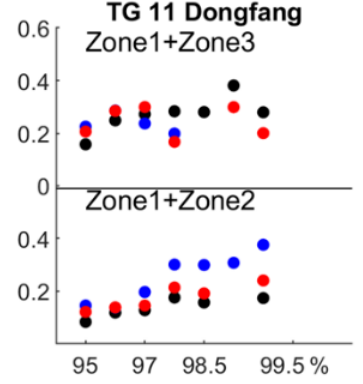

(c)

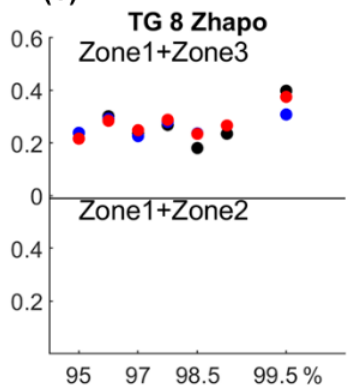

- TC (Jul-Oct)

- $\quad$ Summer (Jun-Aug)

- Whole year

Figure 5. Kendall dependence between storm surge and precipitation in summer, the TC season, and the whole year for thresholds running from $95 \%$ to $99.5 \%$. (a) Kanmen (TG4); (b) Shanwei (TG6); (c) Zhapo (TG8); (d) Haikou (TG10); (e) Dongfang (TG11).

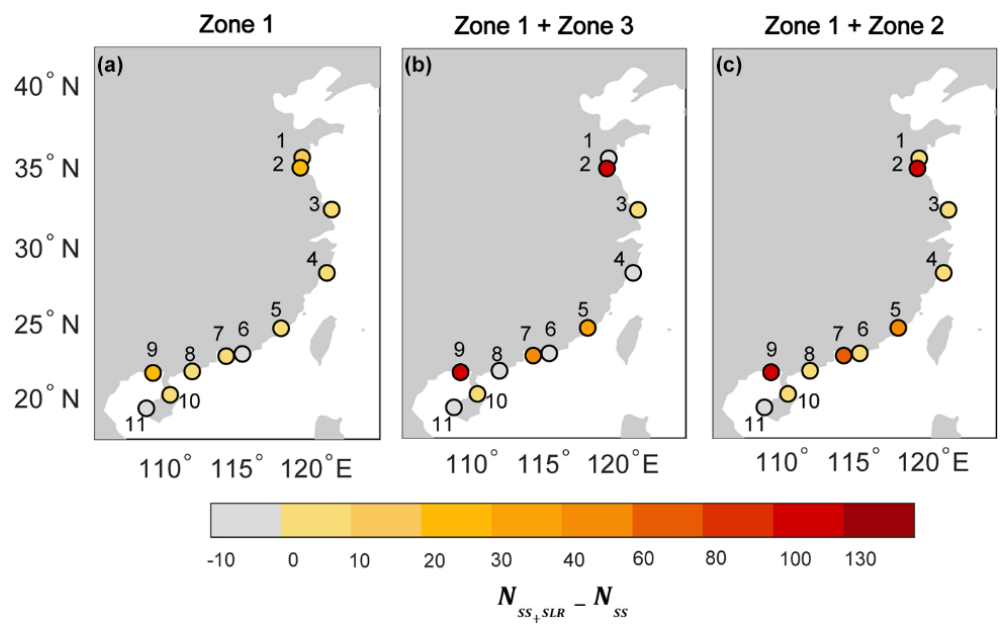

Figure 6. Count of joint occurrences between storm surge and precipitation with/without mean sea level influence at threshold of $98 \%$. $N_{\mathrm{SS}+\mathrm{SLR}}$ indicates joint occurrences considering historical sea level rise trend. $N_{\mathrm{SS}}$ indicates joint occurrences after removing the effects of sea level rise. (a) Zone 1; (b) Zone 1+ Zone 3; (c) Zone 1+ Zone 2.

\subsection{Weather patterns driving events with high and low compound flood potential}

We derived composite plots of synoptic conditions of SLP, PWC, and wind fields that drive joint occurrence events (both high storm surge and heavy precipitation; Zone 1 in Fig. 2) and events where only one driver was extreme (high storm surge or heavy precipitation, Zones 2 and 3 in Fig. 2) across coastal China. To illustrate the results, we focus on Kan- men (TG4) and Shanwei (TG6) on the east and south coast of China, which both have been frequently affected by TCs (Figs. 7 and 8). Results for the other nine stations are shown in Figs. S2-S10. Based on the $98 \%$ threshold we selected to identify joint occurrences, we identify 15 events for Kanmen (TG4) and 21 events for Shanwei (TG6), respectively.

The meteorological patterns in SLP, PWC, and wind fields are distinctly different across the three event types. At Kanmen (TG4), joint occurrence events are associated with a 


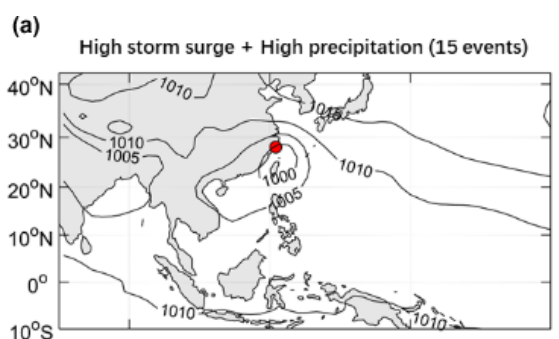

(d) High storm surge + Low precipitation (103 events)

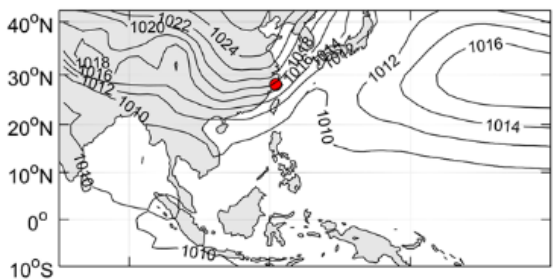

(g)

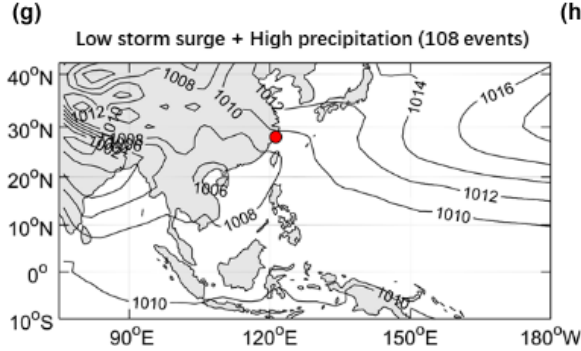

(b)

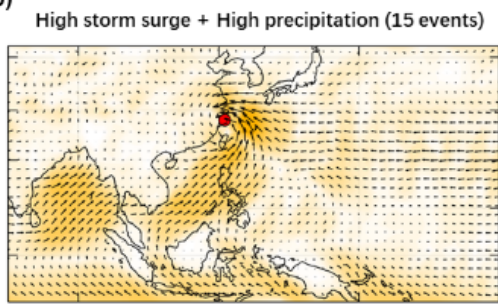

(e)

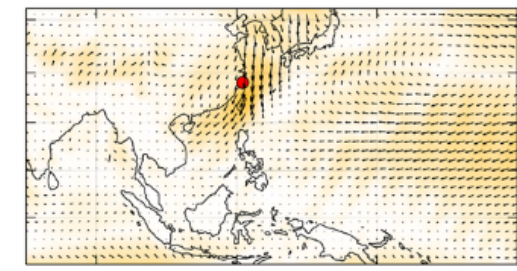

(h)

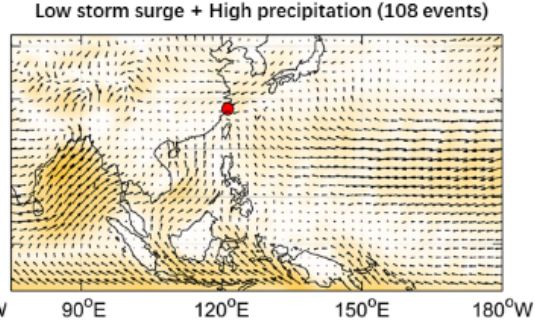

(c)
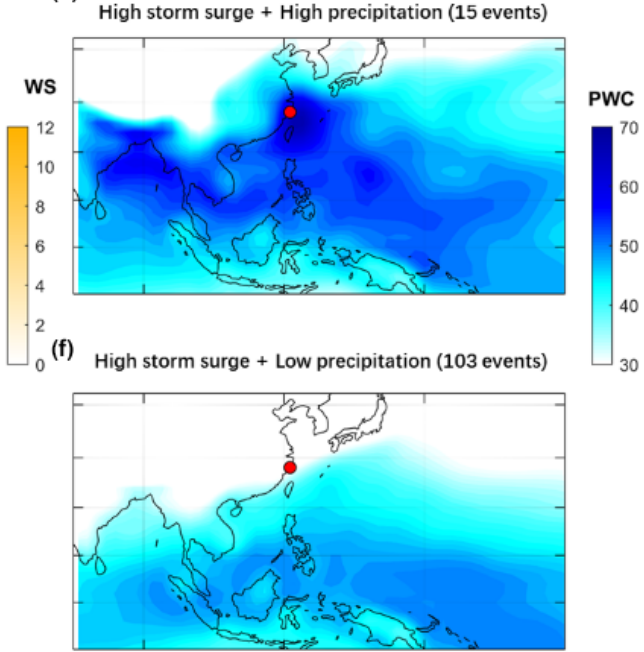

(i)

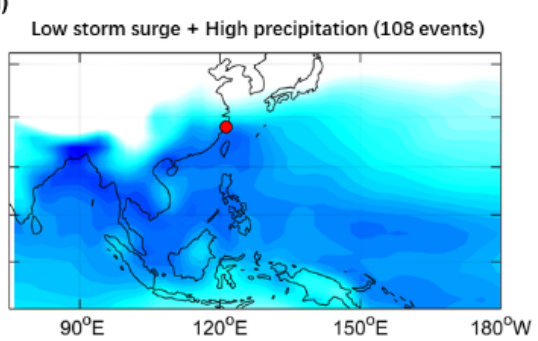

Figure 7. Meteorology conditions for Kanmen (TG4): (a, d, g) sea-level pressure (mbar), (b, e, h) wind speed ( $\mathrm{m} \mathrm{s}^{-1}$ ) and direction (grey arrows), and (c, f, i) precipitable water content (PWC, $\mathrm{kg} \mathrm{m}^{-2}$ ) during (a-c) joint occurrence events with high storm surge and high precipitation (Zone 1), (d-f) for events with high storm surge and low precipitation (Zone 3), and (g-i) events with low storm surge and high precipitation (Zone 2).

well-defined low-pressure system with strong east-west and south-westerly winds transporting moist air toward the southeastern coast of China (Fig. 7a-c). Events with high storm surge and low precipitation exhibit a distinct pressure gradient along the coast (Fig. 7d). As expected, the wind speed is much stronger along the coast for this case (Fig. 7e) compared to the one where only precipitation is high (Fig. 7h), and the northern high wind drives moist air away from the site of interest. The differences in PWC patterns for with high and low compound flood potential are more pronounced (Fig. 7c, f and i). Low storm surge and high precipitation events could also be caused by strong local convective rainfalls, which may not be captured here. There is low PWC for the type of only high storm surge events (Fig. 7f), while high PWC from the Bay of Bengal and cross-equatorial flow is observed for the other two types of events.

At Shanwei (TG6), similarly to Kanmen, the meteorological patterns in SLP show a cyclone structure for both joint occurrence events and events with only high storm surge (Fig. 8a and d). For events with high storm surge only, there is a distinct pressure gradient and strong wind speed (Fig. 8e). The PWC is low for the high storm surge events and high for joint occurrence and high precipitation-only events (Fig. 8c, f and i). For precipitation-only events, flows from the Bay of Bengal and cross-equatorial flow are observed, and southeastern wind drives moist air to the site of interest (Figs. 8b and $7 \mathrm{~h})$.

The results for other stations are similar (Figs. S2-S10). For joint occurrence events, synoptic weather patterns for south-eastern TG sites (latitude $<30^{\circ} \mathrm{N}$ ) show similar lowpressure systems carrying intense PWC and causing strong wind. For northern TGs, such as TGs 1-3 (Figs. S2-S4), the low-pressure systems are less developed compared to other TG sites. As most TCs make landfall along the south-eastern China coasts, their intensity decreases when they move from south to north (see also Fig. 1).

\subsection{Losses of past TC events where compound flood potential was high or low}

Based on the flooding driver information (storm surge and precipitation), we identify 315 events in total for Hong Kong, including 44 events in Zone 1, 116 events for Zone 2, and 155 events for Zone 3 in Fig. 9. The damage database does not include information on all events that we identified, as it is a historical TC disaster damage dataset, meaning 
(a)

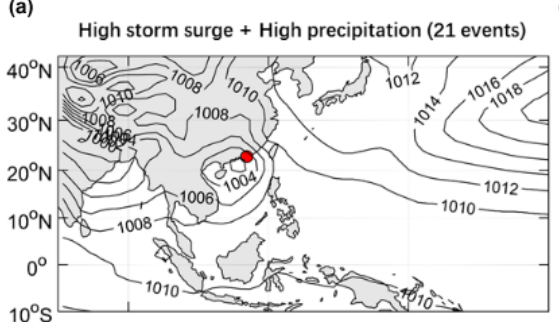

(d)

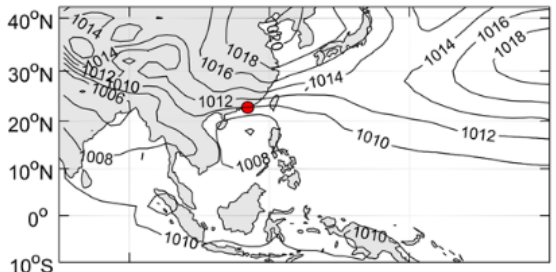

(g)

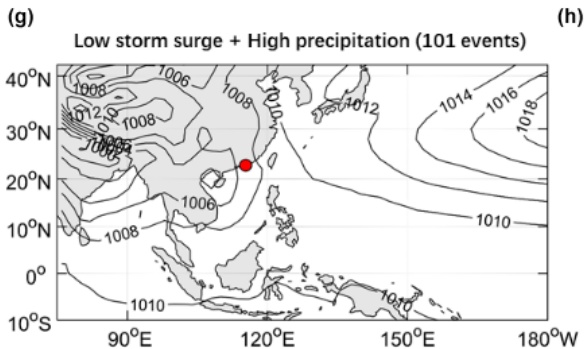

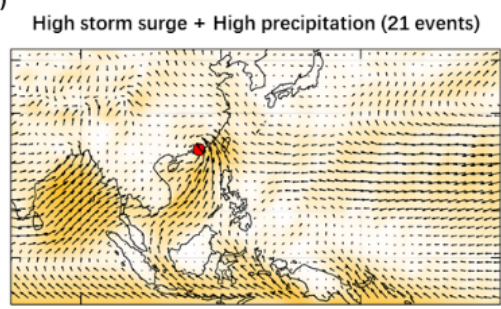

(e)

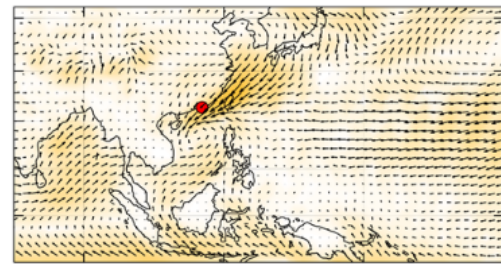

(h)

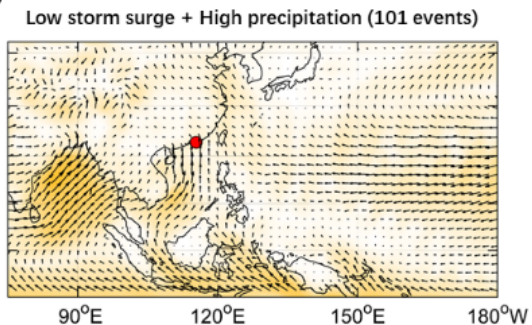

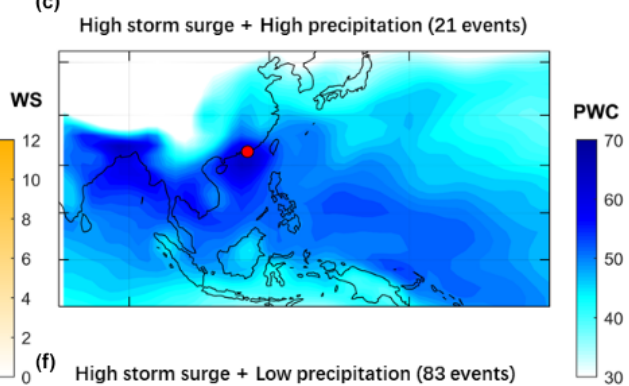

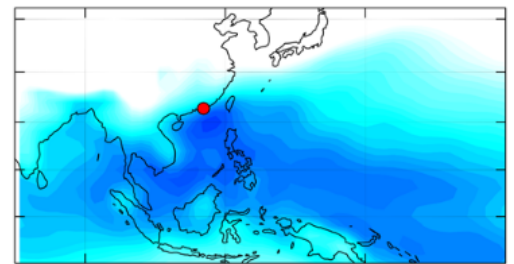

(i)

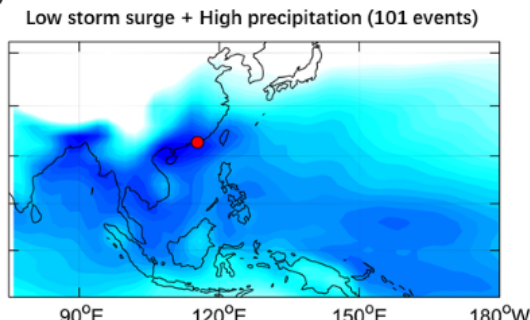

Figure 8. Meteorology conditions for Shanwei (TG6): (a, $\mathbf{d}, \mathbf{g})$ sea-level pressure (mbar), (b, e, h) wind speed $\left(\mathrm{m} \mathrm{s}^{-1}\right)$ and direction (grey arrows), and (c, $\mathbf{f}, \mathbf{i})$ precipitable water content $\left(\mathrm{kg} \mathrm{m}^{-2}\right)$ during $(\mathbf{a}-\mathbf{c})$ joint occurrence events with high storm surge and high precipitation (Zone 1), (d-f) for events with high storm surge and low precipitation (Zone 3), and (g-i) events with low storm surge and high precipitation (Zone 2).

that events that are not associated with a TC are excluded. None of the 168 events which are identified based on storm surge and precipitation data but not included in the damage database were joint occurrences where both flooding drivers were extreme. A total of $68 \%$ of those unmatched events (115 events) are identified as low storm surge and high precipitation and hence more likely related to convective rainfall events. It also indicates that not all those events led to significant damages or the damages was not recorded. As shown in Fig. 9b, joint occurrences caused 227 deaths (average 5 deaths per event), affected 29550 people (672 affected people per event), and led to USD 221 million (average USD 5 million per event) damages. Events with lower compound flood potential where only one driver was extreme caused 65 deaths (average 0.24 deaths per event), affected 6469 people (23.87 affected per event), and caused USD 0.92 million (USD 0.003 million) recorded damages. Hence, joint occurrence events contributed $78 \%$ of the reported causalities, $82 \%$ of the people affected, and the vast majority of recorded damages. It is difficult to exactly quantify the contributions of compound flooding events to the impacts, as reported historical damage records could contain inaccuracies and inconsistencies, such as various reported numbers from different sources and incomplete information. Furthermore, the TC damages not only result from flooding due to heavy rainfall and storm surge, but also include damages from other effects, such as gales (strong winds). From the perspective of disaster system theory (Shi et al., 2020), it is also related to vulnerability and human activities. Due to the complexity of damage records themselves, unfortunately, there is no straightforward way to disentangle the fraction that each hazard contributed to the recorded damages, but nevertheless the analysis highlights the importance of joint occurrence with high compound flood potential in causing damages in highly urbanized areas.

\section{Discussions}

The findings presented here are consistent with previous studies conducted for other regions, such as USA (Wahl et al., 2015) and Europe (Ganguli and Merz, 2019). On the one hand, significant dependence exists between various flood hazard drivers which should be taken into consideration when drainage systems and other flood mitigation infrastructure are designed. This is of particular im- 
(a)

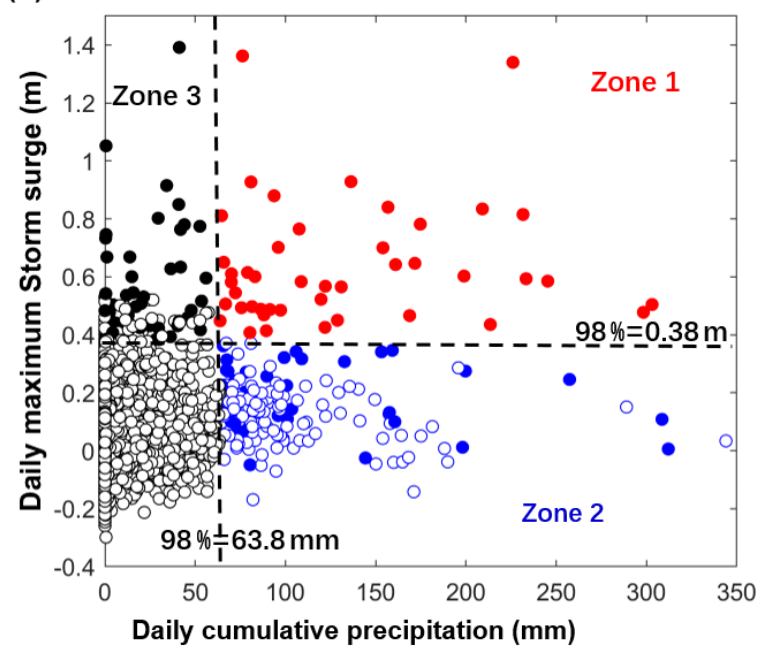

(b)
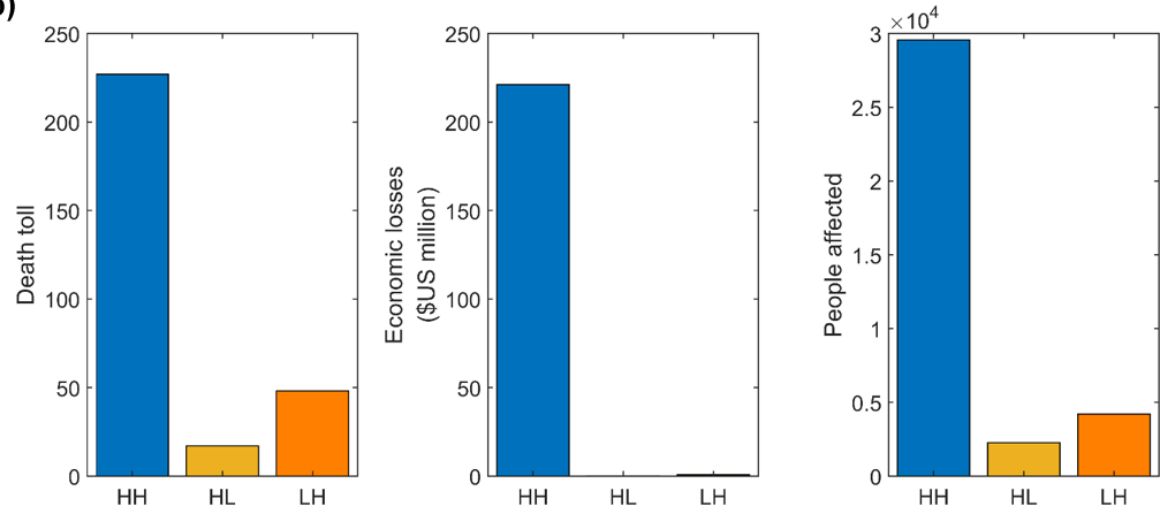

Figure 9. (a) Daily maximum storm surge plotted against daily cumulative precipitation for threshold of $98 \%$ for Hong Kong. Filled dots indicate events linked to TC historical damage records. (b) Damages by joint occurrences (HH: high storm surge and high precipitation) flood and events where only one flood driver was extreme (HL refers to high storm surge and low precipitation; LH refers to low storm surge and high precipitation) in Hong Kong.

portance for coastal China, as China was the country with the fastest growing number of artificial impervious areas between 1985-2018 and now ranks first globally in terms of total impervious area (Gong et al., 2019). On the other hand, our results indicate that the frequency of compound events is increasing for coastal China under climate change, in particular sea level rise, which is also in line with previous studies (Moftakhari et al., 2017; Bevacqua et al., 2019). Additional drivers of climate change and variability could further exacerbate the associated flood impacts (Liu et al., 2018). There is evidence, for example, that El Niño-Southern Oscillation (ENSO) has an impact on the dependence between storm surge and precipitation in Australia (Wu and Leonard, 2019). Hence, future research should focus on the interaction between climate processes (e.g. El Niño and/or rising temperatures) and different flooding drivers, such as storm surge, precipitation, river discharge, and waves, and their joint occurrences as well as the associated impacts. The latter are often hard to quantify without using computationally expen- sive hydrologic and hydraulic models. Eilander et al. (2020) firstly conducted a global analysis forced by a multi-model ensemble of global hydrological models and bounded downstream by a global tide and surge model. Other studies are usually limited to local applications as opposed to larger regional assessments.

One of the main limitations of this study is the relatively small number of tide gauge sites and limited length of the time series available, especially from TGs. For now, publicly accessible datasets considered here constitute the most comprehensive collection of hourly sea level data along Chinese coasts. There is an urgent need for longer data sets to be used in order to better assess compound flood risk, especially for south-eastern China coasts which are prone to TCs. Here we only consider two drivers of flooding: precipitation and storm surge. The role of other flooding drivers needs to be further explored, as well as compound effects under nonstationary conditions, including bivariate frequency analysis, assessing the relationship to climate indices, and the implications for 
flood risk management. The latter is particularly important, given the low capacity of drainage systems in many Chinese urban areas.

\section{Conclusions}

In this study, we assess the compound flood potential from storm surge and precipitation along major stretches of coastal China. The results show that significant dependence exists between the two flood drivers at many locations, especially at sites in lower latitudes (latitude $<30^{\circ} \mathrm{N}$ ). The dependence varies when using different thresholds in the event sampling and is also affected by seasonality. The latter shows that compound events occur more often during the TC season, especially in summer. We also find that sea level rise plays an important role in causing more frequent events with high compound flood potential, and it is expected that continuing and accelerating sea level rise will further increase the compound flooding risk. From the perspective of weather patterns, joint occurrence events at south-eastern TG sites (latitude $<30^{\circ} \mathrm{N}$ ) are caused by low-pressure systems of similar characteristics carrying intense PWC and causing strong winds that generate storm surges. For Hong Kong, we find that TC events where compound flood potential was high were responsible for the vast majority of the recorded casualties and damages, as opposed to events where compound flooding potential was low because only one driver was extreme.

Ignoring compound effects likely leads to an underestimation of flood risk in coastal China, particularly along the south-eastern coasts. It is therefore crucial that coastal cities and urban planning authorities address compound flood effects (including additional drivers such as river discharge or waves) when designing coastal infrastructure and flood defences or developing adaptation plans to combat the negative impacts of climate change.

Data availability. This study relies entirely on publicly available data from (1) hourly sea level data of 11 TGs with at least 20year lengths along the Chinese coast from the University of Hawaii Sea Level Center (https://doi.org/10.7289/V5V40S7W, Caldwell et al., 2015); (2) cumulative daily precipitation records from 19512015 collected from China Meteorological Administration (http: //data.cma.cn/, last access: 1 July 2018; China Meteorological Data Service Centre, 2018); (3) meteorological data from the 20th Century Reanalysis, Version 2c, obtained from the National Oceanic and Atmospheric Administration website (http://www.esrl.noaa. gov/psd/data/gridded/data.20thC_ReanV2.html, last access: 1 December 2019; NOAA, 2019); and (4) historical damage records from a typhoon database developed by Yap et al. (2015) including historical typhoon records from 1951 to 2012.
Supplement. Sensitivity of threshold on correlation (Fig. S1) and meteorological patterns for events with high compound flood potential and low compound flood potential at the other nine TGs (not shown in the article) are shown in Figs. S2S10. The supplement related to this article is available online at: https://doi.org/10.5194/hess-25-4403-2021-supplement.

Author contributions. JF (first author) and WT conceived and planned the study. JF (first author) carried out the analysis and prepared the paper. WT provided guidance on compound flood analysis and contributed to interpretations. JF (third author), FK, XS, and ML offered their expertise in flood, heavy precipitation, and hydrometrology and contributed to revising the manuscript

Competing interests. The authors declare that they have no conflict of interest.

Disclaimer. Publisher's note: Copernicus Publications remains neutral with regard to jurisdictional claims in published maps and institutional affiliations.

Special issue statement. This article is part of the special issue "Understanding compound weather and climate events and related impacts (BG/ESD/HESS/NHESS inter-journal SI)". It is not associated with a conference.

Acknowledgements. This work is funded by the National Natural Science Foundation of China (grant nos. 42001096 and 42077441), the National Key R \& D Program of China (grant no. 2017YFC1503001), the Shanghai Sailing Program (grant no. 19YF1413700), and the China Postdoctoral Science Foundation (grant no. 2019M651429). Thomas Wahl acknowledges funding support from the National Science Foundation (grant no. 1929382).

Financial support. This research has been supported by the National Natural Science Foundation of China (grant nos. 42001096 and 42077441), the National Key R \& D Program of China (grant no. 2017YFC1503001), the Shanghai Sailing Program (grant no. 19YF1413700), the China Postdoctoral Science Foundation (grant no. 2019M651429), and the National Science Foundation (grant no. 1929382).

Review statement. This paper was edited by Jakob Zscheischler and reviewed by four anonymous referees. 


\section{References}

Arns, A., Wahl, T., Haigh, I. D., Jensen, J., and Pattiaratchi, C.: Estimating extreme water level probabilities: a comparison of the direct methods and recommendations for best practise, Coast. Eng., 81, 51-66, https://doi.org/10.1016/j.coastaleng.2013.07.003, 2013.

Bevacqua, E., Maraun, D., Vousdoukas, M. I., Voukouvalas, E., Vrac, M., Mentaschi, L., and Widmann, M.: Higher probability of compound flooding from precipitation and storm surge in Europe under anthropogenic climate change, Sci. Adv., 5, eaaw5531, https://doi.org/10.1126/sciadv.aaw5531, 2019.

Bevacqua, E., Vousdoukas, M. I., Shepherd, T. G., and Vrac, M.: Brief communication: The role of using precipitation or river discharge data when assessing global coastal compound flooding, Nat. Hazards Earth Syst. Sci., 20, 1765-1782, https://doi.org/10.5194/nhess-20-1765-2020, 2020.

Buchanan, M. K., Oppenheimer, M. and Kopp, R. E.: Amplification of flood frequencies with local sea level rise and emerging flood regimes, Environ. Res. Lett., 12, 064009, https://doi.org/10.1088/1748-9326/aa6cb3, 2017.

Caldwell, P. C., Merrifield, M. A., and Thompson, P. R.: Sea level measured by tide gauges from global oceans - the Joint Archive for Sea Level holdings (NCEI Accession 0019568), Version 5.5, [data set], NOAA National Centers for Environmental Information, https://doi.org/10.7289/V5V40S7W, 2015.

Chen, W. B. and Liu, W. C.: Modeling flood inundation induced by river flow and storm surges over a river basin, Water, 6, 31823199, https://doi.org/10.3390/w6103182, 2014.

Cheng X.: Flood Risk and Flood Management Policies in China, in: Annual Report on China's Response to Climate Change (2017), Research Series on the Chinese Dream and China's Development Path, edited by: Wang, W. and Liu, Y., Springer, Singapore, 2020.

China Meteorological Data Service Centre: http://data.cma.cn/, last access: 1 July 2018.

Coles, S., Bawa, J., Trenner, L., and Dorazio, P.: An introduction to statistical modeling of extreme values, in: Vol. 208, Springer, London, 2001.

Compo, G. P., Whitaker, J. S., Sardeshmukh, P. D., Matsui, N., Allan, R. J., Yin, X., Gleason, B. E., Vose, R. S., Rutledge, G., Bessemoulin, P., and Brönnimann, S.: The twentieth century reanalysis project, Q. J. Roy. Meteorol. Soc., 137, 1-28, 2011.

Couasnon, A., Eilander, D., Muis, S., Veldkamp, T. I. E., Haigh, I. D., Wahl, T., Winsemius, H. C., and Ward, P. J.: Measuring compound flood potential from river discharge and storm surge extremes at the global scale, Nat. Hazards Earth Syst. Sci., 20, 489-504, https://doi.org/10.5194/nhess-20-489-2020, 2020.

Ding, X. L., Zheng, D. W., Chen, Y. Q., and Huang, C.: Sea level change in Hong Kong from tide gauge records, J. Geospat. Eng., 4, 41-50, 2002.

Du, S., He, C., Huang, Q., and Shi, P.: How did the urban land in floodplains distribute and expand in China from 1992-2015?, Environ. Res. Lett., 13, 034018, https://doi.org/10.1088/17489326/aaac07, 2018.

Eilander, D., Couasnon, A., Ikeuchi, H., Muis, S., Yamazaki, D., Winsemius, H. C., and Ward, P. J.: The effect of surge on riverine flood hazard and impact in deltas globally, Environ. Res. Lett., 15, 104007, https://doi.org/10.1088/1748-9326/ab8ca6, 2020.

Fang, J., Liu, W., Yang, S., Brown, S., Nicholls, R. J., Hinkel, J., Shi, X., and Shi, P.: Spatial-temporal changes of coastal and marine disasters risks and impacts in Mainland China, Ocean Coast. Manage., 139, 125-140, https://doi.org/10.1016/j.ocecoaman.2017.02.003, 2017.

Fang, J., Lincke, D., Brown, S., Nicholls, R. J., Wolff, C., Merkens, J. L., Hinkel, J., Vafeidis, A. T., Shi, P., and Liu, M.: Coastal flood risks in China through the 21st century An application of DIVA, Sci. Total Environ., 704, 135311, https://doi.org/10.1016/j.scitotenv.2019.135311, 2020.

Fang, J., Wahl, T., Zhang, Q., Muis, S., Hu, P., Fang, J., Du, S., Dou, T., and Shi, P.: Extreme sea levels along coastal China: uncertainties and implications, Stoch. Environ. Res. Risk A., 35, 405-418, https://doi.org/10.1007/s00477-020-01964-0, 2021.

Fang, Y., Du, S., Scussolini, P., Wen, J., He, C., Huang, Q., and Gao, J.: Rapid Population Growth in Chinese Floodplains from 1990 to 2015, Int. J. Environ. Res. Publ. Health, 15, 1-11, https://doi.org/10.3390/ijerph15081602, 2018.

Feng, J., von Storch, H., Jiang, W., and Weisse, R.: Assessing changes in extreme sea levels along the coast of China, J. Geophys. Res.-Oceans, 120, 8039-8051, https://doi.org/10.1002/ 2015JC011336, 2015.

Feng, J., Li, D., Wang, T., Liu, Q., Deng, L., and Zhao, L.: Acceleration of the Extreme Sea Level Rise Along the Chinese Coast, Earth Space Sci., 6, 1942-1956, https://doi.org/10.1029/2019EA000653, 2019.

Feng, X. and Tsimplis, M. N.: Sea level extremes at the coasts of China, J. Geophys. Res.-Oceans, 119, 1593-1608, https://doi.org/10.1002/2013JC009607, 2014.

Ganguli, P. and Merz, B.: Trends in compound flooding in northwestern Europe during 1901-2014, Geophys. Res. Lett., 46, 10810-10820, https://doi.org/10.1029/2019GL084220, 2019.

Gong, P., Li, X., Wang, J., Bai, Y., Chen, B., Hu, T., Liu, X., Xu, B., Yang, J., Zhang, W., and Zhou, Y.: Annual maps of global artificial impervious area (GAIA) between 1985 and 2018, Remote Sens. Environ., 236, 111510, https://doi.org/10.1016/j.rse.2019.111510, 2019.

Hao, Z., Singh, V. P., and Hao, F.: Compound extremes in hydroclimatology: a review, Water, 10, 718, https://doi.org/10.3390/w10060718, 2018.

He, H., Yang, J., Gong, D., Mao, R., Wang, Y., and Gao, M.: Decadal changes in tropical cyclone activity over the western North Pacific in the late 1990s, Clim. Dynam., 45, 3317-3329, https://doi.org/10.1007/s00382-015-2541-1, 2015.

He, H., Yang, J., Wu, L., Gong, D., Wang, B., and Gao, M.: Unusual growth in intense typhoon occurrences over the Philippine Sea in September after the mid-2000s, Clim. Dynam., 48, 1893-1910, https://doi.org/10.1007/s00382-016-3181-9, 2016.

Hendry, A., Haigh, I. D., Nicholls, R. J., Winter, H., Neal, R., Wahl, T., Joly-Laugel, A., and Darby, S. E.: Assessing the characteristics and drivers of compound flooding events around the UK coast, Hydrol. Earth Syst. Sci., 23, 3117-3139, https://doi.org/10.5194/hess-23-3117-2019, 2019.

Hu, P., Zhang, Q., Shi, P., Chen, B., and Fang, J.: Floodinduced mortality across the globe: Spatiotemporal pattern and influencing factors, Sci. Total Environ., 643, 171-182, https://doi.org/10.1016/j.scitotenv.2018.06.197, 2018.

Jiang, T., Su, B., Huang, J., Zhai, J., Xia, J., Tao, H., Wang, Y., Sun, H., Luo, Y., Zhang, L., and Wang, G.: Each $0.5^{\circ} \mathrm{C}$ of warming increases annual flood losses in China by more than 
60 billion USD, B. Am. Meteorol. Soc., 101, E1464-E1474, https://doi.org/10.1175/BAMS-D-19-0182.1, 2020.

Khanal, S., Ridder, N., Terink, W., and Hurk, B. V. D.: Storm surge and extreme river discharge: a compound event analysis using ensemble impact modelling, Front. Earth Sci., 7, 224, https://doi.org/10.3389/feart.2019.00224, 2019.

Kojadinovic, I. and Yan, J.: Modeling multivariate distributions with continuous margins using the copula R package, J. Stat. Softw., $34,1-20,2010$.

Kundzewicz, Z. W., Su, B., Wang, Y., Xia, J., Huang, J., and Jiang, T.: Flood risk and its reduction in China, Adv. Water Resour., 130, 37-45, https://doi.org/10.1016/j.advwatres.2019.05.020, 2019.

Lai, Y., Li, J., Gu, X., Chen, Y. D., Kong, D., Gan, T. Y., Liu, M., $\mathrm{Li}, \mathrm{Q}$., and $\mathrm{Wu}, \mathrm{G} .:$ Greater flood risks in response to slowdown of tropical cyclones over the coast of China, P. Natl. Acad. Sci. USA, 117, 14751, https://doi.org/10.1073/pnas.1918987117, 2020.

Leonard, M., Westra, S., Phatak, A., Lambert, M., van den Hurk, B., McInnes, K., Risbey, J., Schuster, S., Jakob, D., and StaffordSmith, M.: A compound event framework for understanding extreme impacts, Wiley Interdisciplin. Rev.: Clim. Change, 5, 113128, https://doi.org/10.1002/wcc.252, 2014.

Lian, J. J., Xu, K., and Ma, C.: Joint impact of rainfall and tidal level on flood risk in a coastal city with a complex river network:a case study of Fuzhou City, China, Hydrol. Earth Syst. Sci., 17, 679689, https://doi.org/10.5194/hess-17-679-2013, 2013.

Liu, J., Wen, J., Huang, Y., Shi, M., Meng, Q., Ding, J., and Xu, H.: Human settlement and regional development in the context of climate change: a spatial analysis of low elevation coastal zones in China, Mitig. Adapt. Strat. Global Change, 20, 527546, https://doi.org/10.1007/s11027-013-9506-7, 2015.

Liu, Z., Cheng, L., Hao, Z., Li, J., Thorstensen, A., and Gao, H.: A Framework for Exploring Joint Effects of Conditional Factors on Compound Floods, Water Resour. Res., 54, 2681-2696, https://doi.org/10.1002/2017WR021662, 2018.

Marcos, M., Rohmer, J., Vousdoukas, M. I., Mentaschi, L., Le Cozannet, G., and Amores, A.: Increased Extreme Coastal Water Levels Due to the Combined Action of Storm Surges and Wind Waves, Geophys. Res. Lett., 46, 4356-4364, https://doi.org/10.1029/2019GL082599, 2019.

Moftakhari, H. R., Salvadori, G., AghaKouchak, A., Sanders, B. F., and Matthew, R. A.: Compounding effects of sea level rise and fluvial flooding, P. Natl. Acad. Sci. USA, 114, 9785-9790, https://doi.org/10.1073/pnas.1620325114, 2017.

NOAA: Twentieth Century Reanalysis (V2): Summary, [data set], available at: http://www.esrl.noaa.gov/psd/data/gridded/ data.20thC_ReanV2.html, last access: 1 December 2019.

Paprotny, D., Vousdoukas, M. I., Morales-Nápoles, O., Jonkman, S. N., and Feyen, L.: Compound flood potential in Europe, Hydrol. Earth Syst. Sci. Discuss. [preprint], https://doi.org/10.5194/hess2018-132, 2018.

Pawlowicz, R., Beardsley, B., and Lentz, S.: Classical tidal harmonic analysis including error estimates in MATLAB using T_TIDE, Comput. Geosci., 28, 929-937, 2002.

Petroliagkis, T. I., Voukouvalas, E., Disperati, J., and Bidlot, J.: Joint probabilities of storm surge, significant wave height and river discharge components of coastal flooding events, JRC Tech- nical Reports, European Commission, Italy, ISBN 978-92-7957665-2, https://doi.org/10.2788/677778, 2016.

Qin, H. P., Li, Z. X., and Fu, G.: The effects of low impact development on urban flooding under different rainfall characteristics, J. Environ. Manage., 577-585, https://doi.org/10.1016/j.jenvman.2013.08.026, 2013.

Salvadori, G., Durante, F., De Michele, C., Bernardi, M., and Petrella, L.: A multivariate copula-based framework for dealing with hazard scenarios and failure probabilities, Water Resour. Res., 52, 3701-3721, https://doi.org/10.1002/2015WR017225, 2016.

Shi, P., Ye, T., Wang, Y., Zhou, T., Xu, W., Du, J., Li, N., Huang, C., Liu, L., Chen, B., and Su, Y.: Disaster Risk Science: A Geographical Perspective and a Research Framework, Int. J. Disast. Risk Sci., 11, 1-15, https://doi.org/10.1007/s13753-020-002965, 2020.

Svensson, C. and Jones, D. A.: Dependence between extreme sea surge, river flow and precipitation in eastern Britain, Int. J. Climatol., 22, 1149-1168, https://doi.org/10.1002/joc.794, 2002.

Svensson, C. and Jones, D. A.: Dependence between sea surge, river flow and precipitation in south and west Britain, Hydrol. Earth Syst. Sci., 8, 973-992, https://doi.org/10.5194/hess-8-973-2004, 2004.

Urban Planning \& Design Institute of Shenzhen: Detailed Planning for Reclaimed Water and Stormwater Utilization in Guang-ming New District in Shenzhen, China, 2008.

van den Hurk, B., van Meijgaard, E., de Valk, P., van Heeringen, K. J., and Gooijer, J.: Analysis of a compounding surge and precipitation event in the Netherlands, Environ. Res. Lett., 10, 035001, https://doi.org/10.1088/1748-9326/10/3/035001, 2015.

Wahl, T., Jain, S., Bender, J., Meyers, S. D., and Luther, M. E.: Increasing risk of compound flooding from storm surge and rainfall for major US cities, Nat. Clim. Change, 5, 1093, https://doi.org/10.1038/nclimate2736, 2015.

Ward, P. J., Couasnon, A., Eilander, D., Haigh, I. D., Hendry, A., Muis, S., Veldkamp, T. I., Winsemius, H. C., and Wahl, T.: Dependence between high sea-level and high river discharge increases flood hazard in global deltas and estuaries, Environ. Res. Lett., 13, 084012, https://doi.org/10.1088/1748 9326/aad400, 2018.

Wu, L., Wang, B., and Geng, S.: Growing typhoon influence on east Asia, Geophys. Res. Lett., 32, 109-127, https://doi.org/10.1029/2005GL022937, 2005.

Wu, S., Feng, A., Gao, J., Chen, M., Li, Y., and Wang, L.: Shortening the recurrence periods of extreme water levels under future sea-level rise, Stoch. Environ. Res. Risk A., 31, 2573-2584, https://doi.org/10.1007/s00477-016-1327-2, 2017.

$\mathrm{Wu}, \mathrm{W}$., and Leonard, M.: Impact of ENSO on dependence between extreme rainfall and storm surge, Environ. Res. Lett., 14, 124043 , https://doi.org/10.1088/1748-9326/ab59c2, 2019.

Wu, W., McInnes, K., O’grady, J., Hoeke, R., Leonard, M., and Westra, S.: Mapping dependence between extreme rainfall and storm surge, J. Geophys. Res.-Oceans, 123, 2461-2474, https://doi.org/10.1002/2017JC013472, 2018.

Xing, Z., Yan, D., Zhang, C., Wang, G., and Zhang, D.: Spatial Characterization and Bivariate Frequency Analysis of Precipitation and Runoff in the Upper Huai River Basin, China, Water Resour. Manage., 29, 3291-3304, https://doi.org/10.1007/s11269015-0997-8, 2015. 
Xu, H., Xu, K., Lian, J., and Ma, C.: Compound effects of rainfall and storm 33, 1249-1261, https://doi.org/10.1007/s00477-01901695-x, 2019.

Xu, K., Ma, C., Lian, J., and Bin, L.: Joint probability analysis of extreme precipitation and storm tide in a coastal city under changing environment, PloS One, 9, e109341, https://doi.org/10.1371/journal.pone.0109341, 2014.

Yap, W., Lee, Y., Gouramanis, C., Switzer, A. D., Yu, F., Lau, A. Y. A., and Terry, J. P.: A historical typhoon database for the southern and eastern Chinese coastal regions, 1951 to 2012, Ocean Coast. Manage., 108, 109-115, https://doi.org/10.1016/j.ocecoaman.2014.05.024, 2015.

Ye, Y. and Fang, W.: Estimation of the compound hazard severity of tropical cyclones over coastal China during 19492011 with copula function, Nat. Hazards, 93, 887-903, https://doi.org/10.1007/s11069-018-3329-5, 2018.
Zhai, P., Zhang, X., Wan, H., and Pan, X.: Trends in total precipitation and frequency of daily precipitation extremes over China, J. Climate, 18, 1096-1108, https://doi.org/10.1175/JCLI-3318.1, 2005.

Zheng, F., Westra, S., and Sisson, S. A.: Quantifying the dependence between extreme rainfall and storm surge in the coastal zone, J. Hydrol., 505, 172-187, https://doi.org/10.1016/j.jhydrol.2013.09.054, 2013.

Zheng, F., Westra, S., Leonard, M., and Sisson, S. A.: Modeling dependence between extreme rainfall and storm surge to estimate coastal flooding risk, Water Resour. Res., 50, 2050-2071, https://doi.org/10.1002/2013WR014616, 2014.

Zscheischler, J., Westra, S., Van Den Hurk, B. J., Seneviratne, S. I., Ward, P. J., Pitman, A., AghaKouchak, A., Bresch, D. N., Leonard, M., Wahl, T., and Zhang, X.: Future climate risk from compound events, Nat. Clim. Change, 8, 469-477, https://doi.org/10.1038/s41558-018-0156-3, 2018. 